\title{
EDUCAÇÃO DO CAMPO OU EDUCAÇÃO NO CAMPO?
}

\author{
Prof. Dr. Luiz Bezerra Neto \\ UFSCar \\ lbezerra@ufscar.br \\ Agência financiadora: FAPESP
}

\section{RESUMO:}

O texto apresentado é parte do relatório de pesquisa preliminar, financiado pela FAPESP e que busca discutir os princípios histórico-filosóficos que fundamentam as propostas de educação no MST, sua concepção educacional e sua visão de mundo, visto que esse Movimento entende como inexorável a reforma da educação, adaptada e adequada às condições do meio rural e entendida, a partir desse pressuposto, como instrumento capaz de libertar a classe trabalhadora da exploração a que está submetida, provendo assim o acesso ao saber àqueles que foram de alguma forma, excluídos da sociedade capitalista.

A necessidade de se aprofundar neste tema surgiu a partir do estudo desenvolvido durante a pesquisa realizada para a obtenção do título de mestre, momento em que me dediquei a analisar as práticas educativas e formativas do MST e as experiências de formação desenvolvidas no interior desse movimento. Ao ingressar no programa de doutorado da Faculdade de Educação da UNICAMP, procurei verificar o porquê de propostas semelhantes às do MST, apresentadas na primeira metade do século XX, não terem sido implementadas, ou pelo menos, não terem atingido os resultados esperados à época, ocasionando o retorno de sua apologia na atualidade.

Ao buscar compreender seus pressupostos, pude verificar que este movimento padece de alguns problemas que estão na origem de sua formação, dado que ao aderir ao comunitarismo-cristão e ao pragmatismo, consubstanciado num ecletismo pedagógico fica impossibilitado de compreender a realidade a partir da relação dialética propugnada pelo materialismo histórico, que pretendem aderir.

Palavras-chave: Educação do campo; movimentos sociais; sem terra.

\section{RURAL EDUCATION OR EDUCATION IN A SPECIFIC FIELD}

\begin{abstract}
:
The text presented is part of the preliminary research report, financed by FAPESP and discusses the historical and philosophical principles underlying the proposals for education in MST, its education conception and its world view, because this movement understands as inexorable the education reform, adapted and suited to the conditions of the rural environment and, understood from this assumption, as an instrument to liberate the working class from the exploitation to which it is subjected, thus providing access to knowledge for those who were somehow excluded from capitalist society.

The need to deepen this theme emerged from the study conducted during the survey to obtain a Master's degree, when I've been involved in studying the educational and training practices of MST. When entering the Ph.D. program at the College of Education, UNICAMP, I looked for the reason of proposals similar to the MST, at the first half of the twentieth century have not been implemented, or at least they have not achieved the results expected at the time, causing the return of his apology nowadays.

When trying to understand your assumptions, I have noted that this movement suffers from some problems that have led to its formation, as to join the Christian communitarianism
\end{abstract}


and pragmatism, embodied in an eclecticism when it comes to teaching, it is unable to understand reality from the dialectical relationship advocated by historical materialism, which they aspire to join

Keywords: Rural education, social movements, landless

\section{INTRODUÇÃO}

Este texto resulta de parte do relatório preliminar, de pesquisa financiada pela FAPESP e busca compreender os princípios histórico-filosóficos que fundamentam o projeto educativo do movimento dos trabalhadores rurais sem terra - MST, que propõe uma nova forma de educar a fração da classe trabalhadora que habita no campo, mediante conteúdos específicos para o meio rural, fazendo a apologia de uma pedagogia que vise à fixação do homem no campo.

A pesquisa buscou discutir os princípios histórico-filosóficos que fundamentam as propostas de educação no MST, sua concepção educacional e sua visão de mundo, visto que esse Movimento entende como inexorável a reforma da educação, adaptada e adequada às condições do meio rural e entendida, a partir desse pressuposto, como instrumento capaz de libertar a classe trabalhadora da exploração a que está submetida, provendo assim o acesso ao saber àqueles que foram de alguma forma excluídos, pela sociedade capitalista.

A necessidade de se aprofundar neste tema surgiu a partir do estudo desenvolvido durante a pesquisa realizada para a obtenção do título de mestre, momento em que me dediquei a analisar as práticas educativas e formativas do MST e as experiências de formação desenvolvidas no interior desse movimento. Ao ingressar no programa de doutorado da Faculdade de Educação da UNICAMP, procurei verificar o porquê de propostas semelhantes às do MST, apresentadas na primeira metade do século XX, não terem sido implementadas, ou pelo menos, não terem atingido os resultados esperados à época, ocasionando o retorno de sua apologia na atualidade.

Pude então verificar que não basta defender a integração do homem com a natureza por meio da formação integrada do trabalho intelectual com o trabalho braçal, visto que são as condições materiais que criarão as condições de sobrevivência dos trabalhadores no campo ou na cidade. Portanto, ao se propor uma nova forma de ensinar e aprender de acordo com a realidade do homem do campo, visando à fixação desse à terra como forma de viabilizar suas lutas pela reforma agrária, o MST, como faziam os defensores do ruralismo pedagógico, deixa de considerar que as bases materiais de determinadas sociedades determinam em última instância as formas de pensar e de agir de seu povo.

\section{O movimento por uma educação do campo e os referenciais pós-modernos em educação}

Mesmo sendo um dos movimentos mais importantes do Brasil a partir do último quarto do século XX, o MST em que pese reivindicar um caráter revolucionário, acaba 
assumindo posturas conservadoras, ao atribuir à educação uma função redentora dos males vividos por nossa sociedade. Seus dirigentes colocam num mesmo patamar a necessidade de se fazer a reforma agrária e o investimento na educação. Para o MST, a conquista da terra de nada adiantará se não vier acompanhada de uma educação voltada para os interesses dos trabalhadores em geral e dos trabalhadores rurais em particular.

A importância desse debate aumenta na medida em que nos últimos anos tem aparecido na agenda de alguns movimentos sociais, sindicais, na academia e nas pautas governamentais, a discussão sobre uma possível necessidade de se construir uma educação específica para aqueles que vivem e trabalham no campo, ou seja, uma educação "do campo".

Iniciaremos por constatar que a partir do final dos anos 1990 e início do século XXI, aparece um movimento autodenominado "Por uma Educação do Campo", cujas bases epistemológicas partem de uma visão na qual o mundo rural é diferente do urbano, como se vivêssemos em duas realidades diferentes, como se rural e urbano não fizessem parte de uma mesma totalidade.

Como esse movimento não trabalha com uma visão de totalidade, passa-se a admitir a existência de um homem urbano e um homem rural, de uma mulher urbana e uma mulher rural, quando não de uma criança rural e de uma criança urbana. Daí a luta por uma escola do campo, diferente da escola urbana. Esta perspectiva nos leva a perguntar: quais as concepções pedagógicas que são utilizadas para se buscar uma educação do campo e quais as matrizes teórico-filosóficas a embasam?

Essa discussão torna-se mais relevante à medida em que o campo brasileiro está longe de ser homogêneo e seus habitantes congregam interesses bastante divergentes, senão vejamos: Os movimentos sociais basicamente relacionam-se com os assentados por programas de reforma agrária, no entanto, temos trabalhadores remanescentes de quilombolas, pequenos proprietários que chegaram a determinadas regiões a partir do processo de migração ocorrido ao longo dos séculos XIX e XX e outros agricultores que habitam determinadas regiões do país a várias décadas e até a centenas de anos e que não se relacionam com os movimentos sociais. Nesse caso, é lícito perguntar: a discussão deveria se dar em torno de uma educação no campo ou uma educação do campo?

Se entendermos que o processo educacional deve ocorrer no local em que as pessoas residem, devemos falar de uma educação no campo e aí, não haveria a necessidade de se pensar em uma educação específica para o campo, dado que os conhecimentos produzidos pela humanidade devem ser disponibilizados para toda a sociedade.

Se entendermos que deve haver uma educação específica para o campo, teríamos que considerar as diversidades apontadas acima e perguntarmos, de que especificidade estamos falando? Partindo deste pressuposto, teríamos que considerar a possibilidade de uma educação para os assentados por programas de reforma agrária, outra para imigrantes, outra para remanescentes de quilombolas e tantas outras quantas são as diferentes realidades do campo. Nesse caso, trabalharíamos apenas com as diversidades e jamais com o que une todos os trabalhadores, que é o pertencer a uma única classe social, a classe dos desprovidos dos meios de produção e por isso, vendedores de força de trabalho, explorados pelo capital.

O movimento "Por uma Educação do Campo" nasceu nos debates que se fizeram no interior do MST por uma "escola diferente" no início dos anos 1990 (MST, 2005), ganhando corpo em 1998, quando ocorreu em Brasília o I ENERA - Encontro Nacional de 
Educação da Reforma Agrária, desconsiderando a categoria totalidade, uma vez que não relacionam as formas atuais de produção da vida sob o capital com a necessidade de formação que propõem. Segundo Oliveira (2008), a necessidade de uma educação do campo, já pressupõe uma divisão fenomênica entre o rural e o urbano, como se ambos existissem separadamente.

Por desconsiderar a categoria "totalidade", esse movimento não consegue pensar a realidade como objetiva e, assim, não trabalha com a idéia da necessidade do conhecimento objetivo, científico, mas apenas com o "saber dos agricultores" (OLIVEIRA, 2008), fazendo com que os defensores da escola "do campo", não percebam que num momento de crise do sistema capitalista, em que se tem que negar a possibilidade do entendimento da realidade objetiva, negue-se as categorias de historicidade e contradição, tão caras ao materialismo histórico.

Nesse sentido, o movimento "por uma educação do campo" ao defender seus projetos não considera a categoria, contradição, quando tomada como a relação entre contrários que se excluem e se determinam, veem somente vantagens num modelo que apresenta sua lógica pautada numa agricultura familiar ou camponesa, como no caso do MST. No entender de Oliveira (2008),

Os projetos de educação do campo por não trabalharem com as categorias totalidade, historicidade e contradição também não levam em consideração a categoria mediação. Tal atitude deve ser compreendida dentro da perspectiva fenomênica em que tentam captar a realidade, atitude esta que considera não haver diferença entre essência e aparência, uma vez que os fatos se bastam em seus aspectos fenomênicos, ou seja, busca analisar o real em sua mera aparência.

Outro aspecto importante para a compreensão da escola do campo é o conceito de práxis, uma categoria importante para o entendimento das epistemologias dos projetos de educação do campo. Para o marxismo, mais que interpretar a realidade, interessa transformá-la, o que coloca a prática, como o início da ciência social. Para alterá-la, entretanto, é necessário entendê-la. Neste sentido, o entendimento da realidade não pode ser feito sem a mediação de conhecimentos teóricos, entendidos estes enquanto abstrações realizadas a partir de constantes e infinitas aproximações entre a realidade empírica e o conjunto de conhecimentos sobre a realidade, produzidas pela humanidade, por um ramo da ciência e/ou por um pesquisador em especial (OLIVEIRA, 2008).

Por não considerar a teoria como parte imprescindível da formação do concreto pensado, supervalorizando a prática tomada em seu aspecto fenomênico, individual e utilitarista, a educação do campo cai num pragmatismo exacerbado aproximando-se das tendências pós-modernas. Como o pragmatismo se orienta pela ênfase na sua utilidade para determinada pessoa e/ou grupo, dado que o que importa não é buscar as explicações da realidade, mas como viver melhor, encaminhando as situações vividas por um indivíduo, um grupo e/ou mesmo uma sociedade, não há a necessidade do ser humano entender objetivamente a realidade, mas fazer opções de como interpretá-la segundo seus interesses, o que faz do pragmatismo um relativismo filosófico. 
Além do pragmatismo, a pedagogia do Movimento dos Trabalhadores Rurais Sem Terra, assenta-se na pedagogia de Paulo Freire e, segundo Oliveira (2008, p. 392), a partir desta concepção, há uma supervalorização do ensinamento de saberes populares sem que se coloque a mesma importância para o ensino de conhecimentos científicos. Este ideário parte do pressuposto existencialista de que o mundo resume-se ao sentido que cada indivíduo dá a ele, sendo, portanto, função da escola "comunicar os saberes" que cada indivíduo tem deste.

Com isso valoriza-se todo e qualquer tipo de saber construído, ou melhor, consensuado por seus interlocutores, dado que por não existir, nesta concepção, uma verdade objetiva, tudo passa a ser aceito como verdadeiro, desde que haja consenso. Assim passa a ser tido como verdade: conhecimentos, habilidades, sentimentos, valores, modo de ser e de produzir, de se relacionar com a terra e formas de compartilhar a vida. Por isso, os defensores da educação do campo defendem que "[...] a educação desses diferentes grupos tem especificidades que devem ser respeitadas e incorporadas nas políticas públicas e nos projetos pedagógicos (BRASIL, 2004, p. 17).

Assume-se assim, a defesa de uma educação que se constrói a partir da realidade e segundo o MST, se dá porque "[...] a gente foi vendo que queria era uma proposta de educação que não trouxesse as coisas prontas para a criança, e sim que ela construísse a sua própria educação, e que fosse participativa para a escola e os pais" (MST, 2005, p. 17).

Construir o conhecimento a partir da realidade, em nada contraria uma proposta marxiana. Pistrak, por exemplo, sempre recomendou que se partisse da realidade. O problema é o que se entende por realidade, pois nem sempre se compreende que a realidade do sem terra é a realidade de um trabalhador que foi expropriado de suas condições de sobrevivência e que por isso foi obrigado a ocupar terra, participar de acampamentos e depois de assentado, continua integrado ao sistema capitalista e por este explorado. $\mathrm{O}$ que temos observado é que tomando por base a pedagogia piagetiana, o movimento "por uma educação do campo" tem entendido que a escola não deve se pautar por um conhecimento objetivo da realidade, mas pelos saberes de cada indivíduo na sociedade.

A pedagogia tida como ideal para o MST é aquela derivada da pedagogia do oprimido de Paulo Freire. A base desta pedagogia é o existencialismo cristão, sendo que para o existencialista, a existência humana precede a qualquer essência. Por isto, podemos dizer que para o existencialismo, o homem se faz no mundo, ao longo de sua vida, através de suas experiências, seus conflitos, suas conquistas e derrotas, não existindo uma essência do que seja o ser humano. Assim cada indivíduo é um ser particular, que constrói sua própria essência.

Este pensamento é importante para se entender as matrizes do pensamento social na atualidade, inclusive dos movimentos sociais e dos projetos de educação do campo, dado que o existencialismo tem muito de relativista e de irracionalista, já que para o existencialista a verdade depende de um conjunto de escolhas individuais, e do sentido que os indivíduos dão às coisas, o que torna impossível qualquer tipo de conhecimento objetivo. $\mathrm{O}$ existencialismo serve de justificativa para o capitalismo dada a relação entre o que é o mundo e o indivíduo. Para esta corrente, são escolhas feitas pelos indivíduos que permitem à burguesia ligar a idéia de liberdade com liberdade de escolha, idéia tão cara à burguesia para a manutenção de seu sistema. 
Como a realidade é contraditória, histórica e dialética e não apenas uma questão de escolhas de um cientista e/ou de um filósofo, necessitamos de um método para entendêla. Como a realidade é material, entendemos que o melhor método para o seu entendimento é o materialismo histórico e dialético, que vê a realidade como materialista histórica e dialética, buscando entendê-la em toda sua totalidade e complexidade.

Partindo de uma perspectiva marxista, é preciso afirmar que para Marx o ponto de partida do entendimento da coisa em si é a realidade tomada empiricamente mas que, mediante análises sucessivas, tornadas possíveis por um método de investigação específico, permite ao homem ascender à categoria do concreto pensado, ou seja, do real efetivamente existente, que é a realidade como síntese de múltiplas relações - a coisa entendida em sua totalidade e historicidade.

O marxismo se diferencia do existencialismo, por entender que a realidade existe independentemente da consciência sobre ela, dado que o homem tem uma essência, que é sua capacidade de transformar o mundo e criar, em última instância, seu próprio mundo. Já para o existencialista a realidade deriva da consciência sobre o mundo, a ponto de os filósofos existencialistas afirmarem que a "existência precede a essência". Ao contrário do que tem afirmado, tanto o MST como alguns formuladores da proposta de educação do campo, a verdade para o marxismo não está numa teoria, mas numa teoria que corresponda à realidade histórica de uma época, única forma de ser útil para a intervenção na realidade.

O que se tem observado, no entanto, é que os "pós-estruturalistas" buscam estabelecer uma mudança de eixo, um "salto" da realidade para a linguagem como agente constitutivo da consciência humana e da produção social do sentido. Por se visar a produção dos sentidos adere-se a uma suposta sedução da "virada lingüística", levada agora a extremos pela suposição de que há uma anterioridade da linguagem em relação ao mundo real e assim, o que se pode experimentar como "realidade" nada mais seria do que um constructo ou "efeito" do sistema particular de linguagem ao qual pertencemos.

Sendo assim, atribui-se um peso exagerado à linguagem, acreditando-se que é pela linguagem que se domina e que seria por ela que se alcançaria a libertação. Assim passa-se a se referir sempre a todos os homens e todas as mulheres, da mesma forma, falase aos professores e professoras e aos educandos e educandas, quase sempre dando uma predileção para o feminino. Nesse caso, há um deslocamento dos conflitos, das relações de classe para a linguagem, entendendo-se que mudando a linguagem, mudar-se-á o real.

Como na concepção existencialista não existe a possibilidade de conhecer objetivamente a realidade, interessa unicamente buscar o conjunto de interpretações desta, de forma que seja possível o convívio de uma determinada sociedade, justificando-se, a sociedade do capital, à medida que não existe a necessidade de se pensar numa sociedade diferente, mas apenas encontrar caminhos que permitam o desenvolvimento sob a hegemonia do capital. Não é preciso dizer, que esta perspectiva na organização do trabalho pedagógico, significou a passagem da centralidade do conteúdo e do professor para a atividade e o aluno.

Para compreender o surgimento e evolução da proposta sobre a educação do campo, apresentado pelos movimentos sociais e pelos órgãos governamentais, bem como as suas bases filosóficas e epistemológicas é necessário um exame das condições efetivas da realidade, sobretudo a partir da defesa de uma educação "adequada à cultura e à vida dos sujeitos do campo" visando estancar o êxodo rural. Nesse sentido, os ideários dos movimentos sociais que defendem a educação do campo buscam um desenvolvimento que 
traga transformações nas condições de vida das pessoas e das comunidades, sem contudo, reivindicar que estas se dêem fora dos marcos do capitalismo.

Esta perspectiva pode ser confirmada à medida em que de acordo com o Ministério do desenvolvimento agrário:

[...] o desenvolvimento harmônico do meio rural se traduz em crescimento e geração de riquezas em função de dois propósitos superiores: a) coesão social, como expressão de sociedades nas quais prevaleça a equidade, $\mathrm{o}$ respeito à diversidade, à solidariedade, à justiça social, o sentimento de pertencimento e inclusão e b) a coesão territorial como expressão de espaços, recursos, sociedades e instituições imersas em regiões, nações ou espaços supranacionais, que os definem como entidades culturais, política e socialmente integradas (BRASIL, 2003, p. 26).

Devido à pressão dos movimentos sociais que atuam no campo, o Estado, por meio do ministério do desenvolvimento agrário passou a financiar programas de educação do campo propostos por estes movimentos atrelado com a noção de Estado trabalhada por eles. Ainda nas esferas governamentais, podemos observar que os cursos de educação do campo foram alocados no interior da Secretaria de Educação Continuada, Alfabetização e Diversidade - SECAD.

Embora os cursos sejam financiados pelo Estado, como aliás, deve ser, os movimentos sociais tem grande influência em seu debate, como também deve ser. $\mathrm{O}$ problema é que os movimentos que defendem um projeto de educação para o campo, dizem acreditar que com uma educação adequada ao meio rural, o êxodo rural poderia ser solucionado, dado que o grande objetivo desses movimentos sempre foi melhorar as condições de vida do homem do campo que vive em determinadas comunidades. Estes movimentos, dentre eles o MST, compreendem que a crise por que passa o meio rural provêm de uma educação voltada para o meio urbano. Para resolver estes problemas, portanto, haveria a necessidade de uma nova educação que levasse em consideração a realidade do campo.

A presença dos movimentos sociais do campo na discussão sobre a educação, no entanto, é fundamental e, de acordo com Roseli Caldart, o MST vem ajudando a recolocar a questão da educação como

[...] uma das matrizes pedagógicas fundamentais da reflexão de um projeto educativo que se contraponha aos processos de exclusão social, e que ajude a reconstruir a perspectiva histórica e a utopia coletiva de uma nova sociedade com justiça social e trabalho para todos (CALDART, 2001, p. 209).

O MST em vários de seus documentos tem procurado afirmar a importância da educação para a formação humana, por isso, no Dossiê sobre educação, ao discutir os Princípios da Educação do Movimento afirma que: "[...] consideramos a educação uma das dimensões da formação, entendida tanto no sentido amplo da formação humana, como no 
sentido mais restrito de formação de quadros para nossa organização e para o conjunto da luta dos trabalhadores" (MST, 2005, p. 161).

Outro dado relevante a ser discutido sobre a educação do campo é que de acordo com seus formuladores, ela não ocorre somente na escola. Para os educadores do MST, (2005, p. 52), “[...] a primeira coisa que precisamos entender é que a criança não aprende apenas quando está na sala de aula estudando", afirmando ainda que, "[...] para nós, Escola é mais do que aula e aula é mais que repasse de conhecimentos, de conteúdos" (MST, 2005 , p. 213), deixando clara a proximidade da proposta educacional defendida pelo movimento com a proposta de educação construtivista.

Nesse caso, abre-se uma brecha para a adesão à pós-modernidade através das pedagogias do aprender a aprender, tão caras aos defensores do capitalismo, sobretudo, aqueles que pertencem a organismos multilaterais, como o Banco Mundial e o FMI.

É importante ressaltar, até por uma questão de honestidade intelectual para com o movimento, que este considera que é importante a educação escolar, apesar de enfatizar que não é a escola, o único lugar de aprendizagem. Para o MST, sempre cometemos um erro, pois "[...] em geral, e também no caso do MST, sempre associamos muito educação com escola" (MST, 2005, p. 161). Entretanto, a escola que o movimento dos trabalhadores rurais sem terra quer ver construída é uma escola diferente, que leve em consideração as particularidades do meio rural, que visem alterar as condições de vida dos alunos e que permita a construção de um novo sujeito social, um sujeito social Sem Terra, nesse sentido, para o MST, a escola tem que estar ligada às dinâmicas do mundo rural.

De acordo com o MST, o que se defende é a relação necessária que a educação e a escola devem ter com os desafios do seu tempo histórico. Para o movimento, as práticas educacionais que acontecem no meio rural não podem desconsiderar a questão da luta pela Reforma Agrária e os desafios colocados para a implementação de novas relações de produção no campo e na cidade. Sendo assim, o MST defende uma educação voltada para a realidade do meio rural, como sendo aquela que ajuda a solucionar os problemas que vão aparecendo no dia-a-dia dos assentamentos e dos acampamentos, que forma os trabalhadores para o trabalho no meio rural, ajudando a construir reais alternativas de permanência no campo e de melhor qualidade de vida para esta população (MST, 2005, p. $163)$.

Ao definir a sua concepção de educação, o MST afirma que entende por ambiente educativo tudo o que acontece na vida da Escola, dentro e fora dela, desde que tenha intencionalidade educativa, ou seja, desde que seja planejado para que permita certos relacionamentos e novas interações. Nesse caso, não pode ser entendido como educativo apenas o dito, mas o visto, o vivido, o sentido, o participado, o produzido (MST, 2005, p. 213).

Por ser um dos fundadores do "Movimento por uma Educação do Campo", podemos perceber uma relação direta entre o entendimento que o MST expressa sobre o tema na linguagem e na forma com que coloca a necessidade de uma educação do campo a ser realizada com os sujeitos do campo, e nunca para os sujeitos do campo. Para esse movimento, é fundamental que se realize uma educação que dê conta de melhorar as condições de vida dos indivíduos que vivem no meio rural.

De acordo com Caldart, a história da educação escolar no MST acabou transformando as professoras de ofício em uma identidade coletiva específica, que vai além desse ofício, mas que não o abandona. Assim, Caldart entende que a professora sem 
terra é o nome que pode ser dado à personagem do MST que combina em si os componentes identitários diferenciados, cuja síntese pode constitui-se na novidade da conformação histórica do sujeito Sem Terra (CALDART, 2004).

Para os educadores do Movimento, o MST tem uma pedagogia que se desenvolve no jeito por meio do qual vem formando o sujeito social de nome "Sem Terra", e que no dia a dia educa as pessoas que dele fazem parte. Esta é a "Pedagogia do Movimento Sem Terra", cujo sujeito educador é o próprio Movimento, não apenas quanto ao trabalho no campo específico da educação, mas também e principalmente quando sua dinâmica de luta e de organização intenciona um projeto de formação humana, que começa com o enraizamento dos sem terra em uma coletividade, que não nega o seu passado e projeta um futuro que eles mesmos poderão ajudar a construir. Ou seja, o MST não aceita uma pedagogia que não seja aquela derivada de suas ações práticas de educação e uma suposta formação humana geral, que são pensadas para formar seu sujeito coletivo, um sujeito sem terra.

Para o Movimento sem terra, nenhuma corrente pedagógica dá conta de refletir sobre sua prática, de ter um conteúdo que reflita sobre a práxis pedagógica do MST, buscando um sentido de movimento pedagógico de práticas que exigiram uma elaboração teórica que por sua vez exigem um salto de qualidade em novas práticas. Neste sentido, a Pedagogia do Movimento forma-se a partir da mistura de várias teorias pedagógicas que pretendem misturar correntes filosóficas, entre elas o marxismo e o idealismo existencialista, numa base eclética, utilizada como método de formação.

Como o objetivo declarado pelos movimentos sociais é criar melhores condições de vida, os novos paradigmas de educação e de desenvolvimento, voltados para uma perspectiva de transformação do social e do humano, consolidam-se a partir de sua capacidade de prometer o aumento do potencial transformador dos sujeitos - tanto social quanto econômico - investindo no processo de informação e reflexão a partir da decodificação da realidade e de melhores serviços que possam favorecer este movimento, tais como: a educação, a capacitação, a saúde, a alimentação, e a tecnologia, assegurando que os frutos do desenvolvimento econômico favoreçam a melhoria da qualidade de vida.

Como o objetivo final é a transformação da realidade, de forma que os movimentos sociais e as pessoas da comunidade sejam beneficiadas, passa-se a defender que as pessoas ligadas aos movimentos sociais sejam consideradas protagonistas da história e não apenas receptáculos de resultados de ações demandadas de ambientes exógenos e distanciados de seus interesses. Com isto, busca-se favorecer o desenvolvimento local enquanto estratégia de ação, voltada a um possível desenvolvimento com eqüidade atribuindo à educação um papel fundamental na transformação social.

De acordo com o Ministério do desenvolvimento agrário, a educação do campo traz um conjunto de conhecimentos e práticas que instiga as políticas a compreenderem o campo como um espaço emancipatório, como um território fecundo de construção da democracia e da solidariedade, sobretudo a partir do momento em que se passa a acreditar que este se transformou no lugar, não apenas das lutas pelo direito a terra, bem como pelo direito à educação, à saúde entre outros (BRASIL/MDA/SDT, 2006, p. 9-11).

Os defensores da educação do campo, dentre eles o MST, alegam que tradicionalmente o rural aparece como o local da produção agropecuária, do atraso, da pobreza, da falta de estruturas e da carência de serviços públicos, por isso, o espaço rural é sempre tido como o espaço do que "sobra" dos municípios, já que o importante parece ser 
as cidades, mesmo que não passem de pequenos e médios centros que gravitam em torno do trabalho, da produção, da cultura diretamente vinculada ao meio ambiente (BRASIL/MDA/SDT, 2006, p. 9-11).

É neste sentido que de acordo com o MDA, por meio da

[...] multiplicidade de experiências educativas desenvolvidas por diferentes instituições foi construindo uma proposta pedagógica que contempla a identidade do campo, a heterogeneidade dos sujeitos sociais que vivem e/ou trabalham direta ou indiretamente com o meio ambiente, que reconhece o modo próprio de vida dos espaços da floresta, da pecuária, das minas, da agricultura, dos pescadores, dos caiçaras, ribeirinhos e extrativistas. $\mathrm{O}$ desenvolvimento territorial requisita que essas experiências sejam reconhecidas em sua amplitude e diversidade e que busquemos superar a fragmentação e o isolamento de muitas dessas iniciativas, que não têm alcançado o grau de institucionalização, de articulação dessas práticas na perspectiva de contribuir com a política educacional e de desenvolvimento que estamos construindo em nosso país (BRASIL/MDA/SDT, 2006, p. 9-11).

É importante observar que os técnicos desse órgão governamental partem de uma concepção de Educação que se dá como formação e emancipação humana, em que os seres humanos nascem inconclusos, inacabados, e vão se tornando humanos ou se desumanizando no decorrer da vida de acordo com as experiências individuais, coletivas e dos grupos sociais com os quais se convivem e nos quais estes homens se inserem (BRASIL/MDA/SDT, 2006, p. 11-12).

É possível perceber que os defensores da educação do campo, sobretudo aqueles que atuam no programa nacional de educação na reforma agrária/pronera, defendem que

A educação enquanto formação humana constitui em uma ferramenta fundamental para o desenvolvimento econômico, social, cultural e político de seus protagonistas e para construção de uma participação mais crítica e efetiva dos sujeitos, o que implica uma incorporação de responsabilidades individuais e coletivas por suas ações, da necessidade de relacionar e interagir com outros indivíduos para avançar na gestão das políticas e das comunidades onde vivem - no desenvolvimento do capital humano e social (BRASIL/MDA/SDT, 2006, p. 9-11).

Ao defender que a educação constitui-se no grande fator de desenvolvimento, passa-se a entender a educação como um dos componentes do capital humano, tal como ocorria com as políticas tecnicistas instituídas durante o regime civil-militar, instaurado na década de 1960 no Brasil. Assim, afirma-se que

É o desenvolvimento do capital humano e social na população rural, seu "empoderamento", a força que permite ativar os esforços 
coletivos, públicos e privados, que leva ao aumento do emprego e da renda, que aprimora a qualidade de vida e que possibilita às comunidades rurais influírem nas decisões que afetam seu destino (BRASIL/MDA/SDT, 2006, p. 11-12).

Apontando ainda que

A educação como emancipação humana compreende que os sujeitos possuem história, participam de lutas sociais, sonham, tem nomes e rostos, gêneros, raças e etnias diferenciadas e que ao lutar pelo direito à terra, à floresta, à água, à soberania alimentar, aos conhecimentos potencializadores de novas matrizes tecnológicas, da produção a partir de estratégias solidárias vão recriando suas pertenças, reconstruindo a sua identidade na relação com a natureza e com sua comunidade. Essa relação, presente dentro da escola, possibilita uma reavaliação do passado, através do resgate da memória e dos conhecimentos socialmente sistematizados pela humanidade. É uma indagação sobre as barreiras que no presente se colocam a nossa condição humana de seres livres, conscientes e responsáveis e, a partir da produção desses conhecimentos nos remete a construir um futuro solidário, portanto, a luta por educação se vincula com o conjunto das lutas pela transformação das condições sociais de vida no campo (BRASIL/MDA/SDT, 2006, p. 11 e 12).

Os formuladores das políticas de educação do campo apresentam uma visão individualista ao falar na necessidade de educação dos sujeitos que vivem no campo, uma vez que dizem entender que a identidade da educação do campo se constrói pelos sujeitos sociais a quem se destina, e seu modo próprio de vida na utilização do espaço vivido, que se faz ao se redesenhar o papel que a escola deve desempenhar no processo de inclusão das pessoas, como ferramenta estratégica na construção de um projeto de desenvolvimento sustentável e solidário. Nesse sentido, eles entendem que,

[...] o campo tem despontado como um celeiro de iniciativas educativas inovadoras envolvendo os movimentos sociais, ONG's, pastorais, prefeituras e escolas de formação sindical que estão redesenhando o papel que a escola deve desempenhar no processo de inclusão das pessoas, como uma ferramenta estratégica na construção de um projeto de desenvolvimento sustentável e solidário. Portanto, a identidade da educação do campo se constrói pelos sujeitos sociais a quem se destina, e seu modo próprio de vida na utilização do espaço vivido. Assim, incorporam agricultores(as) familiares, assalariados(as) rurais, assentados(as), ribeirinhos(as), caiçaras, extrativistas, pescadores(as), remanescentes de quilombos, indígenas, enfim, todos os povos do campo brasileiro, sejam os que vivem no meio rural, seja os que vivem nas sedes dos 4.485 Municípios rurais do nosso País. Enfim, não existe no campo 
uma única fisionomia. Não podemos pensar uma escola do campo como sendo homogênea, como se só houvesse um sujeito da aprendizagem; os sujeitos do campo são plurais, nos aspectos culturais, sociais, ambientais, de gênero, geração, raça e etnia, portanto, plurais precisam também ser as escolas. Trata-se de combinar formas de fazer uma educação que construa e cultive identidades, auto-estima, valores, memória coletiva que sinalize futuro, saberes e que enraíze sem necessariamente fixar as pessoas. Estar enraizado é se reconhecer como tendo participação ativa no real, bem como se sentir pertencendo a determinado grupo e espaço (BRASIL/MDA/SDT, 2006, p. 12-13).

Esta concepção educacional advém do fato de que o Movimento sem terra foi criado no interior das igrejas, tendo como base, a Teologia da Libertação que a partir do concílio vaticano II e das conferências realizadas em Medelín e Puebla passou a elaborar uma crítica ao capitalismo dependente do Brasil, da América Latina e da África, “[...] propondo uma ruptura radical com o desenvolvimentismo e um compromisso dos cristãos com a práxis libertadora das classes oprimidas: o aspecto fundamental da fé é a práxis histórica" (LOWY, 2007, p. 311), afetando diretamente a as propostas de educação do campo.

Segundo Mônica Molina, uma das principais entusiastas da educação do campo, a escola do campo indica

[...] a unidade na diversidade. Mas, também indica as diferenças entre o campo e a cidade. Além disso, os sujeitos sociais do campo possuem uma base sócio-histórica e uma matriz cultural diferentes, o que os faz demandantes de políticas públicas específicas (MOLINA, 2008, p. 29).

A luta pela educação do sujeito que vive no e do campo inicia-se na década de 1980, com o surgimento e organização do MST, mas o início de uma tentativa de "articulação" por um projeto de educação do campo, que derivaria em um "Movimento por uma Educação do Campo", deu-se no âmbito da I CNEC - Primeira Conferência Nacional de Educação do Campo, organizada pelo MST, em conjunto com a UNB, CNBB e UNICEF, em Brasília, no mês de julho de 1997.

Desde o início dos anos 1980, estava presente no MST e, posteriormente, no movimento "por uma educação do campo", a concepção da necessidade de uma educação específica para a população rural, como se esta tivesse que ser diferenciada da educação da população urbana, deixando claro que os proponentes de tal movimento consideram o homem rural como sendo um ser que vive em uma realidade diferente e não integrada à realidade do homem urbano.

Para justificar o uso da expressão "campo", na conferência que discutiu a possibilidade de uma educação específica em 1997, o MST, por meio de um de seus intelectuais orgânicos argumentava que a defesa do termo campo em oposição ao rural se daria, devido ao 
[...] objetivo de incluir no processo da conferência uma reflexão sobre o sentido atual do trabalho camponês e as lutas sociais e culturais dos grupos que vivem hoje e tentam garantir a sobrevivência desse trabalho. Mas quando se discutir a educação do campo se estará tratando da educação que se volta ao conjunto dos trabalhadores e das trabalhadoras do campo, sejam camponeses, incluindo quilombolas, sejam as nações indígenas, sejam os diversos tipos de assalariados vinculados à vida e ao trabalho no meio rural (KOLLING et al, 1999, p. 26).

Defendendo a mesma linha de interpretação e com argumentos semelhantes, Arroyo, Caldart e Molina, afirmam que

Educação do Campo tem compromisso com a vida, com a luta e com o movimento social que está buscando construir um espaço onde possamos viver com dignidade. A Escola, ao assumir a caminhada do povo do campo, ajuda a interpretar os processos educativos que acontecem fora dela e contribui para a inserção de educadoras/educadores e educandas/educandos na transformação da sociedade (ARROYO; CALDART; MOLINA, 1998, p. 161).

A educação do campo reflete ainda, por parte de alguns autores, um certo saudosismo em relação à vida do homem do campo. É nesta perspectiva que estes autores declaram que

A Educação do Campo precisa resgatar os valores do povo que se contrapõem ao individualismo, ao consumismo e demais contravalores que degradam a sociedade em que vivemos. A Escola é um dos espaços para antecipar, pela vivência e pela correção fraterna, as relações humanas que cultivem a cooperação, a solidariedade, o sentido de justiça e o zelo pela natureza. (ARROYO; CALDART; MOLINA, 1998, p. 162).

A existência de certos valores inerentes ao rurícula foi amplamente reivindicada por educadores que durante as décadas de 1930 e 1940, ficaram conhecidos como defensores do ruralismo pedagógico. O ruralismo do século XXI, no entanto, fraciona a sociedade, não apenas na relação entre campo e cidade, mas também numa relação de gênero, afirmando que,

A educação do Campo deve prestar especial atenção às raízes da mulher e do homem do campo, que se expressam em culturas distintas, e perceber os processos de interação e transformação. A Escola é um espaço privilegiado para manter viva a memória dos povos, valorizando saberes e promovendo a expressão cultural onde está inserida. (ARROYO; CALDART; MOLINA, 1998, p. 162). 
É importante atentar para o fato de que estes autores sempre se referem ao homem e à mulher, como se ambos estivessem inseridos numa luta pelo poder, desvinculando a luta dos homens por igualdade, própria da sociedade de classes. Nesse sentido, a divisão de classes perde a relevância pois o que passa a interessar é a luta que deve se dar na relação de gênero, que se pretende corrigir por meio do uso da linguagem, sempre referindo-se a ambos os gêneros e na maioria das vezes, dando predileção ao gênero feminino.

Nesse sentido, passa-se a defender a formação de educadores para o campo, com uma formação específica, e realizada mediante políticas públicas em que os movimentos sociais possam participar em sua elaboração. Assim, defende-se que, "A Educação do Campo deve formar e titular seus próprios educadores, articulando-os em torno de uma proposta de desenvolvimento do campo e de um projeto político pedagógico específico para as suas escolas" (ARROYO; CALDART; MOLINA, 1998, p. 162-163).

É nesse sentido, que os defensores da educação do campo, destacam que

Quando dizemos Por Uma Educação do Campo, estamos afirmando a necessidade de duas lutas combinadas: pela ampliação do direito à educação e à escolarização no campo; e pela construção de uma escola política e pedagogicamente vinculada à história, à cultura e às causas sociais e humanas dos sujeitos do campo, e não um mero apêndice da escola pensada na cidade: uma escola enraizada também na práxis da Educação Popular e da Pedagogia do Oprimido (KOLLING; CERIOLI \& CALDART, 2002, p. 13).

Para Mônica Molina, uma das formas de dar conta de uma educação específica para o campo é privilegiando o protagonismo dos movimentos sociais ligados a ele, "[...] pois um dos objetivos da educação popular é contribuir para criar condições do povo ser sujeito do processo de produção do conhecimento e de sua própria vida" (MOLINA, 2006, p. 12).

De acordo com Miguel Arroyo, a educação do campo tem que levar para a academia a teoria da formação dos profissionais do conhecimento, de professores e professoras todas as discussões sobre modos diversos de produção do conhecimento, não só sobre os produtos do conhecimento, mas sobre os próprios modos de produção do conhecimento, sobre os diversos paradigmas (ARROYO 2006, p. 116).

Ao estabelecer as parcerias para a atuação no campo, o PRONERA em seu manual de operação, afirma que suas

[...] ações são desenvolvidas por meio de parcerias entre órgãos governamentais, instituições públicas de ensino e instituições comunitárias de ensino sem fins lucrativos, movimentos sociais e sindicais de trabalhadores e trabalhadoras rurais e as comunidades assentadas, no intuito de estabelecer uma interação permanente entre sujeitos pela via da educação continuada e da profissionalização no campo (BRASIL, 2004, p. 16). 
Da mesma forma, podemos observar que no Curso de Pedagogia para Educadores do Campo, esta característica aparece uma vez que segundo o MST:

[...] a transformação social é um processo complexo, que não se resume a uma tomada de poder político ou econômico. Ela implica um processo de outras mudanças que serão capazes de construir um novo tipo de poder, não mais opressor e repressor como este que temos sentido tanto em nossa pele! E isso tem a ver com novos valores, novas relações entre as pessoas, homens e mulheres, adultos e crianças, dirigentes de base, novos posicionamentos diante das várias questões da vida (MST, 2005, 162).

Outro aspecto considerado fundamental, tanto pelos movimentos sociais que atuam no campo, como os formuladores das propostas de educação do campo é o trabalho como princípio educativo, que tem servido para orientar o desenvolvimento do programa, de modo a resgatar os valores do trabalho coletivo contribuindo para a autonomia e o empoderamento dos jovens agricultores familiares (BRASIL, 2004, p. 24).

O problema é que nem sempre o trabalho assume a perspectiva da formação para a superação das relações de classe, dado que quase sempre ele é entendido como uma forma de melhorar a vida dos trabalhadores que atuam no campo sem questionar as relações desiguais produzidas no sistema capitalista. Isto aparece muito claramente nos documentos do MST, visto que O MST trabalha com a noção de que deve haver a formação de um sujeito integral, que se eduque em sua complexidade. $\mathrm{O}$ outro problema a ser solucionado está no fato de que a complexidade utilizada pelos teóricos da educação do campo é a complexidade pensada por Edgar Morin, que diz que a formação do indivíduo integral é aquela em que não existe um único elemento que intervêm na formação, mas a relação e a interação desses elementos que chega a produzir um novo efeito a cada pessoa, no qual dificilmente se pode medir a importância de cada um deles.

Nesse sentido, podemos dizer que o MST adota

[...] a interpretação pós-moderna da teoria da complexidade onde se diz que não há como entender um fenômeno por este ser composto de um conjunto de fatores, variáveis a cada caso e cujas relações não podem ser identificadas. Esta é, portanto, outra forma de aproximação ao ideário pós-moderno (OLIVEIRA, 2008, p. 406).

Sendo assim, assume-se uma postura conservadora, baseada no multiculturalismo, em que podemos observar, por exemplo, que "[...] a educação de adultos inclui a educação formal, a educação não-formal e o espectro da aprendizagem informal e incidental disponível numa sociedade multicultural, onde os estudos baseados na teoria e na prática devem ser reconhecidos" (BRASIL, 2004, p. 18).

Apesar de ser um dos proponentes das propostas de educação do campo, seguindo a lógica das teorias utilizadas neste século, no Brasil, é importante notar que o MST não define sua proposta pedagógica nos marcos de nenhum modelo pedagógico tradicional. Ao contrário, procura conjugar várias posturas, unindo a atuação de existencialistas cristãos 
como Paulo Freire, construtivistas como Piaget e marxistas como Makarenko, passando ainda por propostas nacionalistas, como as de Jose Marti.

É graças a estas conjunções de pensamentos, de autores tão díspares que podemos afirmar que o projeto pedagógico do Movimento dos Trabalhadores Rurais Sem Terra é eclético, além de possuir uma concepção em que a educação aparece com uma função redentora da miséria a que a maior parte da sociedade brasileira está submetida.

Ao acreditar na educação como fator de redenção dos trabalhadores, Caldart afirma que deseja uma educação de classe voltada para os interesses dos trabalhadores rurais sem terra, alegando ainda que "[...] se nós não tivermos acesso ao conhecimento, se nós não democratizarmos a educação, nós não conseguiremos construir uma sociedade mais justa e igualitária" (CALDART, 1997, p. 26).

Embora assente-se numa proposta eclética, o MST traz também a reivindicação de uma escola transformadora, como aparece em seu Manifesto das educadoras e educadores da Reforma Agrária ao povo brasileiro, publicado na revista SEM TERRA (n 2 de 1997, p. 28-29), os educadores da reforma agrária caracterizam a educação a partir de seu envolvimento com o dia-a-dia da comunidade, afirmando a todo o povo brasileiro que:

Queremos uma escola que se deixe ocupar pelas questões de nosso tempo, e que ajude no fortalecimento das lutas sociais, e na solução dos problemas concretos de cada comunidade.

Defendemos uma pedagogia que se preocupe com todas as dimensões da pessoa humana e que crie um ambiente educativo baseado na ação e na participação democrática, e na dimensão educativa do trabalho, da cultura e da história de nosso povo.

Acreditamos numa escola que desperte os sonhos de nossa mocidade, que cultive a solidariedade, a esperança, e o desejo de aprender sempre e de transformar o mundo.

Entendemos que para participar da construção desta nova escola nós, educadoras e educadores, precisamos construir coletivos pedagógicos com clareza política, competência técnica, valores humanistas e unidade de ação.

Lutamos por escolas públicas em todos os acampamentos e assentamentos de reforma agrária do país e defendemos que a gestão pedagógica destas escolas tenha a participação da comunidade Sem Terra e de sua organização.

Já nos princípios da proposta pedagógica desenvolvida pelo Movimento dos Trabalhadores Rurais Sem Terra, fica esclarecido o entendimento do que deva ser a escola ideal, que dá a formação necessária ao cidadão militante para que esse possa assumir seu papel social. Nesse sentido:

[...] a escola deve ser o lugar da vivência e desenvolvimento de NOVOS VALORES, como o companheirismo, a solidariedade, a responsabilidade, o trabalho coletivo, a disposição de aprender sempre, o saber fazer bem feito, a indignação contra as injustiças, a 
disciplina, a ternura [...] chegando a uma CONSCIÊNCIA ORGANIZATIVA (CADERNO DE FORMAÇÃO 18, p. 8).

Sendo assim, a escola deve ter como objetivo principal formar pessoas que sejam sujeitos, com capacidade e consciência organizativa, capazes de construir uma nova forma de conviver, de trabalhar, de festejar as pequenas e grandes vitórias dos trabalhadores (CADERNO FORMAÇÃO 18, p. 11), devendo estimular a livre expressão de idéias e sentimentos, com firmeza na luta em defesa dos trabalhadores e ternura no relacionamento com as outras pessoas. A escola deve ser o lugar capaz de cultivar a alegria coletiva e de revolucionar a vida por inteiro.

Entendida dessa maneira, a escola deve ser não somente o lugar de estudo, mas também um lugar de trabalho. Por isso, além das aulas, as crianças devem ter sempre um trabalho (CADERNO FORMAÇÃO 18, p. 12). O Movimento entende que toda criança deve desde cedo buscar ser um trabalhador produtivo, da mesma forma que nos regulamentos das suas cooperativas observam que nenhum adulto de posse de todas as suas faculdades pode se isentar desta lei geral da natureza. Para se comer, é preciso trabalhar, e não somente com o cérebro, mas com as mãos.

Como um dos grandes desafios do MST é eliminar o analfabetismo dos adultos que vivem no campo, eles utilizam-se da metodologia desenvolvida por Paulo Freire para alfabetizar esta parcela da sociedade. É neste sentido que se pode afirmar que a formação de adultos desenvolvida no interior de seus assentamentos e acampamentos é quase toda influenciada pela pedagogia de Paulo Freire, sobretudo por meio da utilização dos temas geradores.

\section{Possibilidades de conclusões}

Ao pensar o mundo de forma fenomênica o MST e a Via Campesina parecem não enxergarem as contradições do capital propondo uma ação que pode significar, ao invés da superação da sociedade capitalista, o represamento destas possibilidades. Sendo assim, a educação do campo torna-se, no sentido dado por Saviani (2007), um novo tecnicismo, adequado ao momento atual do capitalismo.

Por ter base no comunitarismo cristão e adotar o existencialismo cristão como método de compreensão da realidade, o movimento "por uma educação do campo" e o MST adotam uma perspectiva de que são os movimentos de base, mesmo desprovidos de lideranças localizadas, aqueles que devem protagonizar as transformações sociais.

É neste sentido que se pode afirmar que as propostas de educação do campo, ao aderir ao pensamento idealista, derivado de tradições de caráter fenomênicoexistencialistas, expressa em suas concepções, vertentes do pós-modernismo, estruturada em torno do pós-estruturalismo, do neopragmatismo e do neoweberianismo.

Por estar vinculado à concepção supracitada, a educação do campo apresenta um pressuposto neoprodutivista e neotecnicista conectado com o neoconstrutivismo hegemônicos na organização escolar brasileira, restando à escola, e, sobretudo, a escola do 
campo, a atividade de criar conhecimentos, não de transmitir conceitos objetivos para sua socialização com vistas à transformação social.

Sendo assim, ao professor é atribuído o papel de criar condições para que os alunos tomem decisões cada vez mais acertadas e coerentes com a vida do Assentamento e com os princípios do MST. Por isso, o professor tem necessariamente que ser alguém engajado no movimento; caso contrário, a educação não atingirá seus objetivos junto ao educando.

Não se pode, com isso, querer concluir que o movimento ou suas propostas educacionais não sejam válidas, o que não quer dizer que também não possam ser questionadas.

\section{REFERÊNCIAS}

ARROYO, M. G., CALDART, R. S., MOLINA, M. C. (Orgs.). I Conferência Nacional por uma Educação Básica do Campo. Documentos Finais. Luziânia, GO, 27 a 31 jul. 1998.

ARROYO, M. G. A escola do campo e a pesquisa do campo: metas. In: MOLINA, M. (Org.). Educação do campo e pesquisa: questões para reflexão. Brasília: Ministério do Desenvolvimento Agrário, 2006.

BRASIL, MDA/SDT. 2006

BRASIL. MDA/INCRA. Programa Nacional de Educação na Reforma Agrária PRONERA. Manual de Operações. Brasília, 2004.

BRASIL. MDA. Referências para o desenvolvimento territorial sustentável. Brasília: Conselho Nacional de Desenvolvimento Rural Sustentável - CONDRAF. Núcleo de Estados Agrários e Desenvolvimento Rural - NEAD, 2003. Disponível em: $<w w w . m d a . g o v \cdot b r>$.

Caderno de Formação n. 18: O Que Queremos Com as Escolas dos Assentamentos 2a . ed 1993

CALDART, R. S. O MST e a formação dos sem terra: o movimento social como princípio educativo. São Paulo: Estudos Avançados, 2001.

CALDART, R. S. Pedagogia do movimento Sem Terra. São Paulo: Expressão Popular, 2004.

CALDART, Roseli Salete. Educação em Movimento: Formação de educadoras e educadores no MST. Petrópolis: Editora Vozes, 1997.

KOLLING, E. J. et al. Por uma educação básica do campo. Brasília: MST/Unb/CNBB/UNICEF/UNESCO, 1999. 
KOLling, E. J., CERIOLI, P. R., CALDART, R. S. (Orgs.). Educação do campo: Identidade e Políticas Públicas. Articulação Nacional por uma Educação do Campo, Brasília, v. 4, 2002.

LOWY, M. As esquerdas na ditadura militar: o cristianismo da libertação. In: REIS FILHO, D. A. e FERREIRA, J. (Orgs.). As esquerdas no Brasil. 2. v. Nacionalismo e reformismo radical, 1945-1964. Rio de Janeiro: Civilização Brasileira, 2007.

MOLINA, M. C. Educação do campo e pesquisa: questões para reflexão. In: MOLINA, M. (Org.). Educação do campo e pesquisa: questões para reflexão. Brasília: Ministério do Desenvolvimento Agrário, 2006.

MOLINA, M. C. A constitucionalidade e a justicialidade do direito à educação dos povos do campo. In: SANTOS, C. A. dos. Educação do Campo, Políticas Públicas, Educação. Brasília: INCRA/MDA/NEAD, 2008.

MST. Dossiê MST ESCOLA: documentos e estudos, 1990-2001. São Paulo: Editora Expressão Popular, Setor de Educação do MST/Iterra, 2005.

OLIVEIRA, M. A. de. As bases filosóficas e epistemológicas de alguns projetos de educação do campo: do pretendido marxismo à aproximação ao ecletismo pósmoderno. Curitiba, UFPR, setor de educação, Tese, 2008.

Revista Sem Terra, ano 1 n. 2 out./dez. 97

SAVIANI, D. História das idéias pedagógicas no Brasil. Campinas: Autores Associados, 2007.

Artigo recebido em: 18/05/2010

Aprovado em: 9/6/2010 